\title{
AC 2011-839: NEW APPROACH TO TEACH PRODUCT DESIGN THAT BREAKS THE DISCIPLINARY BOUNDARIES
}

\author{
Iem Heng, New York City College of Technology
}

Professor Iem Heng earned his bachelor's degree from Providence College (Providence, RI) with double majors in Pre-Engineering Program and mathematics. In addition, he earned another bachelor's degree from Columbia University (New York, NY) in mechanical engineering and master's in applied mathematics from Western Michigan University (Kalamazoo, MI); his Ph.D. in computational and applied mathematics from Old Dominion University (Norfolk, VA). Before joining the EMT/CET department at City Tech in fall of 2007, he was a faculty member and chair of the CET department at DeVry Institute of Technology (Long Island City, NY). He worked as a researcher for NASA Langley Base in Hampton, VA, for 2 years. His research activities include embedded systems, software development for embedded systems with real time simulation, real time gamming simulation programming, and web application programming.

\section{Andy S. Zhang, New York City College of Technology}

Professor Andy S. Zhang earned his master's in mechanical engineering from the City College of New York in 1987 and his Ph.D. in mechanical engineering from the Graduate Center of the City University of New York in 1995. Prior joining the Mechanical Engineering Technology department at City Tech in 2000, he served as an engineering instructor for the JUMP, an engineering training program sponsored by the New York State Department of Transportation. Professor Zhang's research area includes materials testing, composite materials, $\mathrm{CAD} / \mathrm{CAE}$, robotics and mechatronics, and engineering technology education.

Farrukh Zia, New York City College Of Technology 


\title{
New Approach to Teach Product Design That Breaks the Disciplinary Boundaries
}

\begin{abstract}
This paper presents an initiative and a strategy to teach product design to students in different engineering technology fields through cross departmental collaboration and cooperation between faculty members in the Mechanical Engineering Technology and the Computer Engineering Technology Departments. The work is funded by the National Science Foundation Advanced Technology Education Division (Award No. DUE-1003712) recently awarded to New York City College of Technology.

Traditional approach to teach product design in a college setting was mostly confined by disciplinary boundaries. There were very little or no collaborations among various engineering departments. Advances in computer technology and semiconductor electronics have created a new product design field called mechatronics. Mechatronics treats product design as system design that requires the tight integration of mechanical components, electrical/electronic systems, industrial design ideas, computer-control systems, embedded systems, and intelligent software into the product design and development processes. Most of the products now being developed are mechatronics in nature. To help students to understand the multidisciplinary nature of the product design, various hands-on product design projects have been developed by the faculty members in the two engineering departments. Students from four different fields of the two departments (mechanical engineering technology, industrial design technology, electromechanical engineering technology and computer engineering technology) have been involved in these projects. Students are divided into design teams. Each design team consists of students from different fields. Joint class sessions are being held and taught by faculties from the two departments at different stages of the design project. Students started to gain important experience in team work, time management, and collaboration and cooperation through various design activities. This concurrent engineering and mechatronic design approach, which emphasizes team collaboration, has become the new industry standard in product design and development.
\end{abstract}

Students were given specific mechatronic/robotic design projects that required them to use actual mechanical, electrical/electronic hardware and software that are being currently used by the industry. This enable the instructor to simulate actual product design activities occurred in the industry. Not only were students exposed to the latest mechatronic technology, they also learn the concurrent engineering design approach in the process. Students were provided with a framework of fundamental design knowledge with hands-on cross-disciplinary activities that allow them to develop an interdisciplinary understanding and integrated approach to product design. Through these hands-on activities, students will also learn the concept of product lifecycle management and sharpen their teamwork skills.

\section{Mechatronics: The New Trend in Product Design}

Mechatronics is defined as a design field with multidisciplinary engineering approach. It is the synergistic combination of mechanical engineering, electrical and electronic engineering, 
computer engineering, and systems design engineering in order to design and manufacture useful products. To put into perspective, mechatronics treats product design as a system design that requires the tight integration of mechanical components, electrical/electronic systems, industrial design ideas, computer-control systems, embedded systems, and intelligent software into the product design and development processes. It also requires engineers, technicians, and designers from various disciplines to possess broader knowledge beyond their specialized fields and to work together concurrently ${ }^{1-2}$. This concurrent engineering and mechatronic design approach, which emphasizes team collaboration, has become the new industry standard in product design and development. Mechatronic technology has been identified as one of the top 10 highly influential emerging technologies of the $21^{\text {st }}$ century by MIT's Technology Review and by the International Center for Leadership in Education ${ }^{3-4}$.

\section{Mechatronics Technology Center: Platform for Inter-Departmental Collaboration}

The Mechatronics Technology Center (MTC) provides a unique platform for faculty and students to engage in hands-on work. Faculty members and students from different programs (mechanical engineering technology, electro-mechanical engineering technology, computer engineering technology, and industrial design technology) meet in the center to discuss and share their ideas, to test design concepts, to experiment with and to hold workshops and seminars.

The MTC consists of a new robotic laboratory and several existing laboratories. The existing laboratories are: CAD, Materials Testing, Manufacturing, Control Systems, Instrumentation, and Computer Controlled Systems Laboratories.

These state of the art software and hardware give designers the necessary freedom to choose and test their design ideas. They enable designers to try different options and to offer different design alternatives. New machines such as a CNC milling center, injection molding, water jet, and 3D printers have been utilized by faculty and students to make parts for their design projects.

The robotic laboratory features robotic systems from National Instruments, Lego Mindstorm, and Arduino. These systems have the following unique features:

- Open Architecture. Unlike many other educational robot kits, which provide a fixed configuration and are used mainly for programming, this robot system provides mainly the enabling components used in the industry (robot controller, electrical/electronic devices, motors, sensors, diagnostic software etc). This provides opportunity to create projects to simulate actual industry activities in design, construct, test, evaluate, and program mechatronic products. It emphasizes creative thinking, innovation, problem solving, and hands-on teamwork.

- The Robotic Technology used in the Industry. The National Instrument's state of the art CompactRIO (cRIO) programmable automation controller is used as the robot controller by many companies 5 . The cRIO features embedded real-time processor for reliable stand-alone or distributed operation and is embedded with a Field Programmable Gate Array (FPGA) chip to provide the flexibility, performance, and reliability for custom hardware integration. This will enable us to create projects that touch all aspects of mechatronic design and 
applications. The Lego's Mindstorm NXT Brick and Arduino Micro Controller as the robot controller provide affordable alternatives for students' low cost design projects. They will also be used to teach robot programming and control. These three robotic systems are being used to address different needs of the program.

The details of the state-of-art software and hardware are shown in the following Table 1:

\section{Table 1: Software and Hardware}

\begin{tabular}{|l|l|}
\hline \multicolumn{1}{|c|}{ Software } & \multicolumn{1}{c|}{ Hardware } \\
\hline Pro Engineers, Autodesk Inventor, & CompactRIO, LabVIEW FPGA, NI C Series \\
MasterCAM, Matlab, Maya, LabVIEW, & Module, NI Single-Board RIO, NI myDAQ, \\
NXT Compiler, FIRST Robotic Compiler, & Lego's Mindstorm NXT Brick, FRC, FTC, \\
RobotC, Arduino Compiler, Java NetBeans & Arduino Micro-controller, Netduino Micro- \\
IDE, Micro C and MS Visual Studio & controller, Arduino Shields/Modules, IC \\
Compiler & Atmega328, Pic18 Micro-controller \\
\hline
\end{tabular}

\section{Learning Community: A Unique Environment for Learning}

The participation of students from different engineering and technology programs to solve multidisciplinary design problems has created a new learning community. It gives students new perspectives when dealing with product design issues. Students realize that product design is a system design, not a design of unrelated components. For example: An industrial design of one component might affect the mechanical design of a system, which in turn could affect the selection of electrical/electronic components, and thus the overall performance of a product.

This type of learning environment provides a unique learning opportunity. Students learn the importance of collaboration and cooperation. They have to pay attention to design issues not only in their specialized field, but others as well.

It has been reported that students work well in groups and students learn more from hands-on projects $^{6}$. Group activities make students to be more active and engage in teamwork and collaboration.

\section{Cognitive Environment: Learning by Doing}

A hands-on cognitive apprenticeship-type training approach has been used to effectively deliver the training material. In traditional schooling that has less practical focus on hands-on training, the "practice" of problem solving, reading comprehension and writing is not at all obvious. And the thinking processes are often invisible to both students and teachers. It is very difficult to understand the logic of programming; however, people in general understand better when they see a program that makes a motor turn based on an action of a sensor. This cognitive apprenticeship training makes the process of thinking visible ${ }^{7}$.

Students use actual physical parts in their design projects. In the past, students rely heavily on their computer to come up with the virtual model of the product. Sometimes, it is very difficult 
for the instructor to explain why the model does not work. When students make the physical model, they can test it to verify their original design, and see if the model met with the design specifications.

The Mechatronics Technology Center (MTC) provides a much needed platform for students to experience failure with their design model. "Failure is the mother of success". The cognitive hands-on activities provide college students opportunities to learn from their many failures. Thomas Edison would not have invented the electric light bulb, if he had not went through 3000 plus different experiments and found out that only two of his ideas proved to be true.

The curricula of the three programs will be modified to create cross-departmental design projects. Students will learn how to design, construct, evaluate, operate, and test mechatronic products. Activities include: 3D design and modeling, materials and manufacturing processes selection, mechanical and structural design, electrical/electronic design, computer control with embedded systems, interfacing, programming, and project management. These simulated product design activities will give our students a better understanding of product design processes and provide them with much needed hands-on experience.

Six courses in the three programs will be modified: MECH 2335 - Advanced Dynamics and Kinematics, MECH 2410 - Machine Design, IND 2313 - Industrial Design I, IND 2410 Industrial Design II, EMT 2461 - Electromechanical Systems Software Interface and EMT 2480 - Electromechanical Systems Laboratory. Details of these courses can be found at www.citytech.cuny.edu/academics/deptsites/metech/index.html and www.citytech.cuny.edu/academics/deptsites/cetech/index.html.

\section{Competition Entry: Practicing Design}

Once the students have been taught with the hardware and software, they are able to build a variety of unique and innovative mechatronic prototypes to compete in various college level competitions or showcase at engineering events such as Robotic Innovations Competition and Conference (RICC), ASME IShow, EPA P3 Awards, NCEES Engineering Award, and ASEE Robotics Competition. The competition provides an opportunity for the students to learn from their competitors. It provides the necessary motivation for cross-departmental students to work together as a team in MTC.

Additional hardware acquired by the Mechatronics Technology Center such as various National Instrument's C Series Modules, National Instrument's Single Board Real-time Controller, NI myDAQ, and Arduino Micro Controller and Shields, makes it possible for City Tech students to create these mechatronic projects for competition with other colleges and universities.

\section{Proposed Assessment Plans}

Both formative and summative evaluation tools will be used to assess the effectiveness of the implementation and the outcomes of the project. 
Formative evaluation will be conducted to assess ongoing project activities. It will address whether project is being conducted as scheduled and whether project is meeting stated objectives and goals.

Faculty advisors will monitor the progress regularly. The team will meet every Friday to report progress and to discuss problems encountered.

Summative evaluation will be conducted to assess the project's outcomes after the project is completed. This is to determine to what extent the project met the overall objectives and goal.

A final result of this project will be reported in a future paper.

\section{Conclusion}

Nationally, technician education practice must align with industry practice or face the risk of losing national competitiveness in the new mechatronic product design and development area. New York City College of Technology (NYCCT), as a top producer of associate-degree recipients from underrepresented minority groups, has the opportunity to lead in training technicians to use project-based concurrent design, moving away from the current paradigm of sequential design within disciplinary boundaries to bring educational practice into sync with industry needs. This approach has been proven to drive much higher levels of performance by empowering each participant; speeding development by eliminating resource bottlenecks; and to improve quality and creativity in product development by bringing together multiple perspectives to solve problems and share specialized insights across a range of products ${ }^{8}$.

Our goal is to change the paradigm for technician education in mechanical engineering technology, electro-mechanical technology, and industrial design technology programs by making concurrent design and mechatronics the hallmark of these programs at City Tech. Our objectives are:

- To create a product design/mechatronics technology center (MTC) that provides a hands-on training platform to teach emerging mechatronic product design technology to emulate the robotics training program developed by the Robotics Academy at Carnegie Mellon University.

- To establish linkages through collaborations in a form of partnership that provides a pathway from secondary to post-secondary educational institutions to industry, using mechatronics and concurrent design as the tool. This would enable high schools, two-year and four-year college programs, and the industry to operate synergistically as a system.

- To develop internships to bring workforce training directly into college. This would lead to create a certificate program in providing opportunities for incumbent workforce and high school technology teaches to be trained on emerging mechatronic/robotic technology

- To articulates with 4-year programs in computer engineering technology, industrial design technology, and career and technical teacher education at City Tech as well as other 4-year 
engineering and technology institutions. This would help to establish a pipeline to supply graduates at different levels with well-balanced practical engineering knowledge and adaptable technical skills.

Each program that this paper is aimed at improving plays a vital role in the US economy. Industrial design, for example, has been identified as a crucial element at improving productivity ${ }^{9}$. Industries such as medical devices, consumer electronics, automobiles, and home appliances depend on industrial design for innovation and competitive advantage ${ }^{10-11}$. The technology fields that this program covers in mechatronic technology includes design, materials selection, manufacturing, and testing fields that have been identified by ATE as well as by "Engineer of 2020" report, and elsewhere as vital for the nation's economic prosperity ${ }^{12-13}$.

We believe the project when fully implemented will significantly improve our ability to provide the kind of training that industry is looking for in the mechatronic product design and application. City Tech students will benefit tremendously through these integrated concurrent engineering and mechatronic product design activities. In addition, by introducing the Learning Products Designs through Hands-on Robotics Projects, the impact of NYC public high schools and NYC industry partners will be significant.

\section{Acknowledgement}

The work is partially funded by a grant from the National Science Foundation Advanced Technology Education Division. The award number is NSF ATE No 1003712. The authors appreciate greatly the support from the NSF.

\section{References}

1. David G. Alciatore and Michael B. Histand, "Introduction to Mechatronics and Measurement Systems", Third Edition, McGraw-Hill Company, 2007.

2. W. Bolton, "Mechatronics - Electronic control Systems in Mechanical and Electrical Engineering", $3{ }^{\text {rd }}$ Edition, Prentice Hall, 2003.

3. David Talbot, "10 Emerging Technologies that Will Change the World", Technology Review, February 2003.

4. Willard R. Daggett, "The Education Challenge: Preparing Students for a Changing World", $14^{\text {th }}$ Annual Model Schools Conference, June 25-28, 2006.

5. NI Robotics Platform Used by FRC, http://digital.ni.com/worldwide/bwcontent.nsf/websearch/f70c10117567bbf18625742b00737df5

6. Charles Fadel, "21st Century Skills - From Industry to Education and Back", 2010 NSF ATE PI Conference, October 27-29, Washington DC.

7. Allan Collins, John Seely Brown, and Ann Holum, "Cognitive Apprenticeship: Making Thinking Visible", 21 st Century Learning Initiative, www.21learn.org/arch/articles/brown_seely.html

8. Bill Evans, "Improving Competitive Advantage through Industrial Design”, Medical Device \& Diagnostic Industry (MDDI), November 2005.

9. Uli Mahle, "The Path to Invention", Mechanical Engineering, Vol. 129/No.9 September 2007.

10. Jean Thilmany, "Pushing Productivity - Computer Technology Has a Hand in Cutting Cost and Raising Profits", Mechanical Engineering, Vol.123/No.12 December 2001.

11. G. Gemser and M. Leenders, "How Integrating Industrial Design in the Product Development Process Impacts on Company Performance", Journal of Product Innovation Management, Volume 18, Issue 1, page 28, January 2001. 
12. National Academy of Engineering, "Educating the Engineer of 2020", The National Academies Press, Washington, D.C. 2005.

13. National Academy of Engineering, "The Engineer of 2020", The National Academies Press, Washington, D.C. 2004. 